\title{
EXPERIÊNCIAS FEMININAS: A PARTICIPAÇÃO NOS \\ MOVIMENTOS SOCIAIS E RELAÇÕES FAMILIARES
}

\section{FEMININE EXPERIENCES: PARTICIPATION IN SOC IAL ACTIVITIES AND FAM I LY RELATI ONS}

Fabíola Zioni $^{1}$

ZIONI, F. Experiências Femininas: A Participação nos Movlmentos Sociais e Relações Familiares. Rev. Bras. Cresc. Des. Hum., São Paulo, IV(1), 1994.

Resumo: Este artigo tem como objetivo identificar mudanças nas práticas cotidianas de mulheres integrantes de movimentos sociais, mudanças essas advindas da participação em experiências públicas e coletivas e que apontem para a democratização das relações sociais.

Palavras-chave: movimento social, dinamica familiar, participação popular, espaço público/ espaço privado, cidadania.

Summary: The objective of this article is to identify changes in the daily practices of women who integrate social activities. These changes are a result of the participation in public and collective experiences and they point out the democratization of social relationships.

Key-words: social activity, family dynamics, popular participation, public space / private space, citizenship.

1 Professora Doutora do Departamento de Prátiica de Saúde Pública - Área de Ciências Sociais - Faculdade de Saúde Pública da Universidade de São Paulo.

End.: Av. Dr. Arnaldo, 715, São Paulo - SP, CEP 01246-904 - Fone: (011) 851.S233 ramal 2294. 


\section{INTRODUÇÃO}

\section{O papel da família na construção de novos padrões de sociabilidade}

Esse artigo foi elaborado a partir de depoimentos obtidas junto a mulheres que participavam de experiências públicas e coletivas em um município da Grande São Paulo, experiências essas que se originaram de reivindicações por instalações e/ou melhorias de equipamentos sociais para a região, principalmente na área de saúde.

O objetivo dessas entrevistas consistia em identificar o impacto da participação em movimentos coletivos no que diz respeito à dinamica familiar e à vida privada; em outros termos, pretendia-se identificar como que experiências na esfera pública podem contribuir para elaboração de novas concepções de vida, novos padrões de sociabilidade que inspirem relações menos autoritárias no interior das famílias, redefinindo os papéis sociais de homem / mulher.

A preocupação com a possível democratização do universo familiar vincula-se a uma vertente da produção sociológico contemporânea sobre os Movimentos Sociais.

Ainda que desde o final dos anos 80, os Movimentos Sociais no Brasil tenham perdido bastante visibilidade, não se pode ignorar que essa modalidade de participação política, ao irromper, no final da década de 70, no cenário brasileiro, contribuiu de maneira decisiva para a democratização da sociedade brasileira assim como, através da reivindicação de direitos sociais, colocou em pauta a temática da cidadania, do papel do Estado para a garantia de condições de vida e, mesmo, da legitimidade da participação popular nos processos decisórios.

Depois desse impacto inicial, pelas próprias caracteristicas do processo de transição negociada, o fim do regime militar não significou uma democratização na prática das instituições políticas e sociais brasileiras. Ainda que garantida por Lei desde a Constituição de 1988, a participação popular na condução das políticas sociais tem esbarrado em questões culturais e sociais que impedem ou limitam essa participação. Em outros termos, os Movimentos Sociais teriam perdido a capacidade de inf uir sobre o sistema político, sobre o sistema de tomada de $\sim$ eis $\sim$ es $\sim$ nriitindo a hipótese de que teriam como características intrínsecas uma certa fragilidade e mesmo efemeridade.

Essas considerações sobre os Movimentos Sociais parecem vinculadas às interpretações sociológicos em que o poder político constitui-se como uma categoria central. A luz de outras for- mas de interpretações, porém, poderiam expressar um potencial para criar e experimentar formas diferentes de relações sociais cotidianas cujo potencial de mudança social seria mais significativo do que a capacidade de influir no sistema político.

Um dos autores que se vinculam a esse tipo de interpretação, $\mathrm{T}^{\wedge}$ lllman Evers acredita que "tecnologias, leis, instituições, não poderiam sustentar o sistema dominante por um minuto sequer, não fossem os milhões de pequenas atos cotidianos de obediência inefletida à ordem existente que criam, reproduzem e reforçam as estruturas sociais... $\wedge$ n. Ao desenvolver uma prática que questiona esse "automatismo de obediência...” pela criação de “...espaços de relações mais solidárias, de consciências menos dirigidas pelo mercado ou de valores e crenças diferentes... os Movimentos Sociais teriam condições de se oporem às estruturas sociais de dominação...” (EVERS, 1987) visto que a prática desses movimentos costuma ser orientada contra diferentes formas de alienação: do homem em relação a si mesmo, ao produto do seu trabalho, à natureza e finalmente em relação aos outros homens.

Essa concepção de Movimento Social, como espaço de novos padrões de sociabilidade que se dão no nível cotidiano fazem recair maior atenção da sociologia sobre a dinamica familiar.

Na atualidade brasileira, a importância da farm^1ia para a forma de vida das classes trabalhadoras tem se acentuado, visto que estas têm que enfrentar, de um lado, a persistência de uma pobreza de raízes seculares presente "...nas franjas do mercado de trabalho, no ...mercado informal, nos confins do mundo rural, num Nordeste de pesada herança oligárquica.. evidências de uma lógica excludente...” e de outro lado, o aparecimento "...da face moderna da pobreza: empobrecimento dos trabalhadores urbanos integrados nos centros dinâmicos da economia do país”. (TELT ES, 1993)

Assim, a família constitui-se como elemento chave para aglutinar todos os esforços e tarefas de um cotidiano estafante e vulnerável para a manutenção de uma vida menos ameaçada, ameaça esta imposta pelo antigo e recente cenário da economia e da ordem social no Brasil.

A importância da organização familiar na formaçao da personalidade dos individuos e/ou na socialização das novas gerações constitui-se como um dos poucos assuntos consensuais nas ciências humanas, assim como uma das "verdades” mais enraigadas nos imaginários e representações sociais as mais diversas. 
Espaço tradicional dos conflitos e vivências que dizem respeito ao mundo organizado para o provimento de necessidades individuais, necessidades de caráter econômico e emocional, a família constitui-se como um elemento próprio da esfera privada das relações humanas, do "mundo da vida”, ainda que bastante marcada pela esfera do sistema, ou seja, "o espaço da administração pública moderna e a economia capitalista”. (COSTA, 1994)

Essa centralidade da família, no que diz respeito às esferas públicas e privadas, significa que além de preparar novas gerações para o "mundo da vida e do sistema", pode assumir um papel importante para o desenvolvimento de novos padrões de sociabilidade, elaboração de novas estratégias e maneiras de levar a vida, visto que o espaço familiar pode propiciar o diálogo, a comunicação entre essas duas esferas.

Esse diálogo seria realizado através de um comportamento na esfera pública - a participação nos Movimentos Sociais - que contemporaneamente não tem como única pauta os assuntos do trabalho, de esfera do mercado, da produção capitalista, mas elaboram discursos e proposições sobre novas orientações para o mundo da vida, e a relação entre essas esferas.

\section{A PARTICIPAÇ̃̃O PÚBLICA E AS MUDANCAS NA FAMÍLIA E NO COTIDIANO: TRANSCRIÇÂO RESUMIDA DE UM DEPOIMENTO}

Entre as mulheres que participaram do Movimento de Saúde de um município da Grande São Paulo cuja luta principal dizia respeito à construção de um Hospital Público na região, algumas concordaram em conceder entrevistas sobre o impacto da participação em movimentos coletivos sobre suas vidas particulares.

O depoimento de Lúcia Mara (nome fictício) foi selecionado para apresentação neste artigo por ser bastante explícito em relação ao tema. mação:

Lúcia Mara referindo-se à sua transfor-

- olha aqui: aquela lá eu matei e enterrei.

Infancia e juventude - trabalho e família:

Nascida no interior de São Paulo, Letícia Mara começou a trabalhar cedo, cuidando dos irmãos:

- ...a mãe ia cortar cana e a gente criava os irmãos. Colaborava também no "retiro do leite" levantando às 3 horas da manhã.

\section{Estudo:}

Não era parafilha mulher; seu pai dizia: "Voce vai se casar e seu marido vai se virar para você como eu me viro para sua mãe". Era mentira.. A mãe trabalhava tanto ou mais que o pai. Esse pai que usava a violência como recurso educativo:

- ...na véspera do último Natal eu e meus irmãos ficamos lembrando... o corpo cheio de sangue..., onde o pai batia, saia sangue... Lembran,ca que não provoca revolta: “....agradeço, porque com essa austeridade fiquei homem de bem... diz um irmãos.

\section{Revolta:}

- Uma vez, quando a mãe estava grávida, trabalhando na roça e o pai inventava doença para vir para São Paulo se cuidar. A gente trabalhando e o pai ficando com o dinheiro... começamos a brigar pelos nossos direitos... eu brigava mais... eu lembro...

\section{Lembrança:}

- Apesar de todo esse sofrimento gostaria que toda a família tivesse a família que a gente teve, apesar de tudo, às vezes o pai sentava e contava estarias. Você consegue fazer isso com seus filhos?

\section{A vinda para a capital:}

Uma outra frustra,cão; trabalhar sim, estudar; nãol Empregada em casa de família que seguia à risca as ^7recomenda,cões de seu pai; não sair nem para estudar nem para namorar, trabalhar das 4 às 22 horas:

- Como era etária! namorava dentro da casa da patroa porque meu pai telefonava dizendo para não deixar sair.

\section{Namoro e casamento:}

- Namorei 3 anos, deitei virgem e acordei grávida... não sabia nada. Ninguém me explicava ou deixava ler. Não conseguia burlar a vigilancia. Perguntei para a patroa como tomar remédio para não ter filhos. Ela disse para não tomar porque depois não ia conseguir ter filhos quando quisesse.

A participação na luta por condições de vida/ A igreja e a comunidade eclesial de base:

- O Padre Lufs foi alguém que iluminou meu caminho. A mulherada não se mexia, era tudo parado. O Padre começou a conscientizar: "não adianta oração sem ação"... A gente deve a luta da gente a ele que fez a gente sentir que a mulher não era só para ficar dentro de casa... Mas vai pôr isso na cabeça dos machos... 


\section{O grupo de saúde:}

- Esse grupo saiu do Clube das Mães onde a gente aprendia a cuidar das crianças, evitar verminoses. Daí saiu a luta pelo lixo e depois a questão da saúde da mulher; de que adianta trabalhar, comer bem, você só tem saúde física, não tem saúde mental. Descobrimos um monte de mulher com saúde mental abalada por causa do machismo.

Imagine que nessa época meu marido trancava o portão para eu não ir ao Encontro de $\mathrm{Mu}$ lheres, não adiantava, eu pulava o muro; consegui viver a experiência, enfrentar o marido. Quase cheguei a me separar porque comecei a brigar pelos meus direitos.

Que briga! "Onde se viu uma dona de casa, uma mulher que se diz mãe de família, se meter com gente de faculdade?” Era querer saber, ser de mais! Ele achava que eu ia aprender muito, ia me valorizar demais e esquecer a família. Comecei a mostrar que arroz e feijão não bastava. Eu precisava de mais coisa. Eu não queria isso para meus filhos. Ele ameaçava ir embora Depós que eu comecei a participar da luta procurei trabalho e encontrei serviço por dia: limpeza de casa de família, de prédio que terminava, a sujeira não saía dos dedos, mas esses anos e os anos do movimento foram os que mais vivi.

Fiz o concurso para entrar no Hospital X da prefeitura de..., ele não queria “...coisa de gente vagabunda, funcionário público só assina ponto". Fiz a inscrição e avisei o marido que ia voltar a estudar "...coisa de mulher vagabunda que quer chifre em cabec,a de cavalo”, ele dizia Dia dos pais, todos esperando que eu fizesse almoço. Saí três horas da manhã para fazer o exame em Itaquera. Onze mil fizeram exame para 30 vagas de costureira! Em julho de 90 a notícia de que tinha passado! Não acreditei, confirmei mil vezes, não acreditava que era eu.

Isso para meu marido foi loucura Pior; ia trabalhar em hospital. "Mulher que trabalha em hospital é galinha”. Mas eu escolhi trabalhar no hospital movida pela luta...

Essa vontade de viver, esse empenho, essa vontade de ver as coisas acontecerem é fé. Até meu marido que é ateu já tem um pouco de fé. Ele pede para eu rezar. Ele pode não gostar do que eu faço, das minhas atividades, mas no fundo me aprecia por causa disso. No dia da formatura ele estava bravo, não queria ser padrinho, não ensaiou, mas na hora fez tudo direito "Você me leva onde você quer”, ele disse.

Já falei que vou fazer curso de enfermagem e ele disse: "Enfermeira é galinha de médico”, no fim ele acabou pedindo para não trabalhar só à noite. Devagarinho ele vai engolindo mais. Graças a isso a gente conseguiu mexer com a casa.

Meu salário é para roupa, sapato e comida. Ele cuida da construção. Eu não sei o que ele tem na cabeça. Será ciúmes? Será falta de confiança neles? Um dia ele falou: "Eu não me conformo. Você não é a Lu que eu conheci”. Eu respondi: Olha aí aquela lá eu matei e enterrei.

\section{Mudanças no cotidiano:}

- Foi depois da luta... Foi daí que eu tomei fé para sair para luta e trabalhar fora... quebrei todas as barreiras que eu tinha dentro de casa... e a situação, ela virou, ela se reverteu... eu falo assim de boca cheia.. minha mãe até dá risada: "engraçado, 0 teu marido hoje vem comer no teu prato, né?” Eu falei ...mas é, eu já comi muito no prato dele, então chegou a hora de virar a coisa, né?

Posso ter a alegria de dizer que as coisas estão melhorando, porque com isso eu aprendi a lidar melhor com meus filhos. Eu só tenho filho homem, agora eu tenho liberdade muito grande para conversar com eles. Agente aprendeu muita coisajunto. Ele também escondia as minhas saídas do pai dele... Quando eu chegava ele dizia: "Mãe, foi tudo bem? Você aprendeu mais alguma coisa hoje?” E agora ele começou a trabalhar e disse: "Eu acho um desaforo uma coisa, mãe, o lugar que eu estou trabalhando, a sociedade ainda é muito machista, porque para eu ter um talão de cheque, precisa meu pai assinar, porque não minha mãe?” Então eu achei isso muito bonito, para você ver como isso abriu também a cabeça dele. A sociedade em que a gente vive é muito machista e a gente acaba criando os filhos da gente assim. Eu acho que os meus eu estou tentando criar de uma outra maneira. Passando para a cabecinha deles o que não passou pela cabeça do pai deles, não é? É uma coisa bonita quando ele chega pro pai dele e faz o pai entender as coisas, que mulher também tem direito de correr lá fora.

\section{ALGUMAS OBSERVACÕES À GUISA DE CONCLUSẪO}

Se o depoimento de Lúcia Mara pode ser entendido como paradigmático da situação estudada, sua fala - a título de conclusão - pode ser enriquecida por outras entrevistas com participantes do movimento.

\section{Lúcia Mara destaca:}

- Eu acho que na minha vida foi um grito de liberdade, né? Essa luta surtiu um efeito muito grande na minha vida para mim foi o primeiro passo para a liberdade, porque eu nunca escondia de ninguém as dificuldades que eu tinha para estar lá fora fazen- 
do aquele trabalho.A entrevistada refere-se à oposi,cão do marido que trancava a casa para evitar suas saídas.

- Mas a partir dai eu já tinha tomado pé das coisas lá fora, a partir daí então, eu tive mais coragem para entender que eu tinha direito de estar fazendo aquilo porque era minha vida, eu estava participando da vida de outras pessoas que tinham os mesmos problemas.

A leitura desse e outros depoimentos permite destacar, se não a denúncia, pelo menos a caracterização de uma relação homem / mulher bastante marcada por elementos tradicionais ou mesmo de dominação.

Em uma das entrevistas, Mariana relata sua vinda para São Paulo para encontrar o marido e as dificuldades para criar os filhos e a história de sua participação pública. Nessa fala percebe-se a dificuldade para se estabelecer relações mínimas de solidariedade entre marido e mulher. Para criar os filhos, estabelecer a família, foi necessário percorrer várias vezes a rota, quase um calvário, entre Alagoas e São Paulo. Mesmo assim seu relato não aponta para o estabelecimento de laços de cumplicidade, pelo contrário, mostra espaços definidos e delimitados de ação para cada um. Apesar disso, a mulher conseguiu redefiriir seu papel, elaborar nova concepção de relação entre pais e filhos e desenvolver uma intensa vida pública à revelia do marido. Lúcia Mara, por sua vez, apesar da oposição cerrada do marido, participa dos movimentos, estuda, trabalha fora, consegue uma profissão e, ao mesmo tempo, se não o apoio, pelo menos a aceitação do marido. Sua vivência pública desenvolve a relação familiar, cria novas concepções de relação entre pais e filhos.

A depoente Mariana revela ainda que sua participação nos movimentos mudou sua concepção de vida, de mulher e contribuiu para terminar uma relação que não a satisfazia:

- Através da luta de mulher a gente começou a se desenvolver bastante também... na luta aprendi que a mulher tem direito à convivência dentro de casa com o marido, com os filhos... Porque antigamente a mulher sabia que era subalterna ao homem... eu ouvi minha mãe falar essa história.. eu digo... não sou filha dessa mulher... hoje em dia, depois de aprender na luta que a gente é igual, eu crio meus filhos diferente...

Ao romper com o passado, negando a mãe que lhe quer transmitir sua submissão, a depoente libertou o futuro... seus filhos, outra geração, ela criou "diferente”. Este depoimento parece revelar que a compreensão das relações de submissão foi possível graças à prática pública coletiva e que é através dela que essa relação pode ser transformada.
Se a fala das entrevistadas revela essa transformação, em outras ocasiões, essa fala remete a um mundo bastante diferente.

O cotidiano entrevisto nestes depoimentos supõe relações familiares, de género, bastante autoritárias e violentas; relações essas que se desenvolvem num contexto geográfico e socialigualmente violento, permitindo supor que, no plano público e privado, relações autoritárias continuam bastante presentes, o que pode apontar para o falo de que a superação de relações de dominação não acontece de forma linear, mas sim que novas formas de relação são elaboradas e postas em prática num cenário em que a persistência das anteriores (tanto no nível público como privado) cria uma situação tensa entre eles. Mais do que superar situações, a prática dos movimentos sociais permitiu, no plano privado, a imposição de limites às relações violentas, autoritárias: cada passo no sentido de mudanças pessoais exige negociação, confronto; a relação familiar, ainda que bastante transformada, não implicou numa critica radical mantendo-se fragmentos de uma imagem idealizada de família.

A persistência de relações familiares autoritárias está bastante clara neste texto:

- ...onde o pai batia saia sangue... mas não temos revolta.. agradeço, porque, com essa austeridade fiquei um homem de bem... Apesar de todo esse sofrimento gostaria que toda a família tivesse a família que a gente teve.

Essas relações autoritárias - apesar de não se superarem totalmente - são bastante limitadas a partir da participação nos movimentos sociais.

A biografia de Lúcia Mara vai, portanto, ao encontro de várias afirmações constantes na literatura sobre o efeito libertário e emancipatório da prática nos movimentos sociais em relação às trajetórias individuais conforme seu depoimento, que vale ser destacado novamente:

- Eu acho que na minha vida foi um grito de liberdade, nó! E essa luta surtiu um efeito muito grande na minha vida... eu tive mais coragem... eu tinha direito a estar fazendo aquilo porque era minha vida.

O autoritarismo das relações pais/filhos, marido/mulher encontra paralelo na relação população/serviços de saúde e população/autoridades municipais como se verifica neste depoimento:

- ...eu não sabia o que falar, eu levava um filho ao médico, eu dava papa de farinha para ele, eu tinha medo de dizer pro médico porque tinha medo de levar carão. 
- ...nesse tempo as mães tinham medo de falar com os médicos... de perguntar que doença era dela... essa maldade toda na medicina que Aia aquilo escon $\sim$ i o - como Da vida foi tanto na medicina como na religião - tudo era uma coisa em latim que mnguem podia entender, participar...

A Fito de conclusão Estaca-se os verbos da Cima faia transcrita que foram conjugados no passado. Esse tempo verbal pode indicar a percepção de que 0 medo à autoridade constituída já pode ser Iocalizado no passado assim como a submissão ao marido pertence à outra família, não mais à sua.

Quantas Lúcias Maras / Marianas podem conjugar esses verbos no passado?

\section{BIBLIOGRAFIA}

COSTA, S. Esfera pública redescoberta da Sociedade e movimentos sociais. Novos Etudos, Cebrapo, março, 1994.

EVERS, T. Identidade: a face oculta dos movimentos sociais. Novos Estudos, 39(3), Cebrap, 1987.

TELLES, V S. Pobreza e cidadania. Caderno GR.H., 19, 1993. recebido em: 30/07/94 aprovado em: 26/09/94 